\title{
Mothers' Affective Behavior With Infant Siblings: Stability and Change
}

\author{
Ginger A. Moore, Jeffrey F. Cohn, and Susan B. Campbell \\ University of Pittsburgh
}

\begin{abstract}
To evaluate within-family differences in maternal affective behavior toward siblings, face-to-face interactions were observed between 39 mothers and their firstborn and second-born infants at 2 months of age. Mother and infant affect was coded on a 1-s time base with behavioral descriptors. Mothers were more positive with second-born infants, and second-born infants were more positive than were firstborns. The siblings' affective behaviors were unrelated, but maternal positive affect was both moderately stable between siblings and correlated with each infant's affect. Thus, in the context of stable individual differences in maternal positive affect, siblings experienced unique affective interactions with their mothers as early as 2 months.
\end{abstract}

Current theories of child development emphasize bidirectional processes (Bell, 1968) and assume that children within families often experience interactions with their parents that differ from those of their siblings (Hoffman, 1991). Withinfamily differences in mother's affective behavior toward their infants are of particular interest because of the role maternal affect is thought to play in infants' ability to regulate emotion (Kaye \& Fogel, 1980; Tronick, Cohn, \& Shea, 1986) and in children's emotion development (Malatesta, Culver, Rich-Tesman, \& Shepard, 1989). However, little is known about how similarly or differently mothers express emotion toward children within families.

Variation in maternal affective behavior toward infant siblings may occur systematically in response to moderator variables, such as birth order, or in terms of individual differences in the stability of maternal affect between siblings. Examinations of these effects, however, often have been confounded by comparing firstborn and later-born children from different families or by comparing mothers with siblings at different ages.

The few studies that have used a within-family, same-age design have not found consistent birth order effects. In an early study of 3-month-old first- and second-born siblings (Jacobs \& Moss, 1976), mothers were found to engage in more social, affectionate, and caretaking (except feeding) behavior with firstborns than with second-borns. However, in a problem-solving task with firstborn and second-born siblings at 24 months, mothers were more emotionally supportive and involved with second-borns (Ward, Vaughn, \& Rabb, 1988). In contrast, in a

Ginger A. Moore, Jeffrey F. Cohn, and Susan B. Campbell, Department of Psychology, University of Pittsburgh.

This research was supported by a grant from the National Institute of Mental Health (MH40867). We thank Michael Pogue-Geile for his contributions to this study. Portions of this research were presented at the March 1995 meeting of the Society for Research in Child Development, Indianapolis, Indiana.

Correspondence concerning this article should be addressed to Ginger A. Moore, 604 Old Engineering Hall, University of Pittsburgh, 4015 O'Hara Street, Pittsburgh, Pennsylvania 15260. Electronic mail may be sent via Internet to gmoore@vms.cis.pitt.edu. series of three reports from the Colorado Sibling Study, Dunn, Plomin, and colleagues (Dunn \& Plomin, 1986; Dunn, Plomin, \& Daniels, 1986; Dunn, Plomin, \& Nettles, 1985) reported that change in maternal affectionate behavior between siblings assessed at 12,24 , and 36 months was unrelated to birth order. Each of these studies measured a different aspect of maternal affective behavior, which may account for the inconsistencies in their results.

In terms of individual differences, however, all three studies found moderate stability in maternal affective behavior between siblings, as did a recent examination of mothers observed with their twins at 7 months and at 9 months (DiLalla \& Bishop, 1996). This stability may derive from a response to perceived similarities in siblings, actual similarities in siblings' behaviors, or from characteristic traits of the mothers. In the Colorado Sibling Study, maternal affectionate behavior was unrelated to differences in mothers' perceptions of siblings' difficuitness (Dunn \& Plomin, 1986). Ward et al. (1988) found that stability in maternal emotionally supportive behavior was related to similarities in the siblings' observed behaviors, whereas, with twin siblings, maternal warmth was found to be similar toward siblings even though identical twin pairs behaved more similarly than did fraternal twin pairs (DiLalla \& Bishop, 1996).

Numerous behavior genetics studies have shown that parental affective behavior is influenced by both genetic characteristics of parents and characteristics of the children with whom they interact (see Plomin, 1994, for a review of this research). The moderate stability typically found in parents' affective behavior toward their children is consistent with this research and with set-point, or trait, theories of emotion (e.g., Lykken \& Tellegen, 1996), which propose that individuals have a stable set point of positive affect, with transitory fluctuations in response to environmental factors.

From this trait-emotion perspective, affective expression in adults is generally a stable trait across time and contexts (Diener \& Larsen, 1984). However, clinical depression may influence stability in emotion expression, as mood disorders are episodic, and individuals generally demonstrate higher rates of negative affect and lower rates of positive affect when experiencing an episode of depression (Clark, Watson, \& Mineka, 1994; 
Watson, Clark, \& Carey, 1988). Thus, in addition to response to behaviors of different infants, fluctuations in affect associated with episodes of depression may contribute to instability in maternal affective behavior.

This article reports results from a study of mothers interacting with their firstborn and second-born infants. Over the course of a longitudinal study of the effects of post-partum depression on firstborn infants, several mothers had second children, and data were collected for second-born infants at 2 months of age just as they were for their firstborn siblings. Although complete data were available for only a small number of sibling pairs $(n=$ 39 ), and the observed interactions were brief, this sample is relatively unique and allowed us to examine several questions. Are there birth order effects in maternal affective behavior and maternal perception of infant temperament at this early age? Are maternal affect and perceptions of infant temperament stable between siblings? What are the relative contributions of stability in mothers' affect and concurrent child behavior in predicting maternal affective behavior? Are birth order effects or instability related to change in mothers' initial diagnosis of depression? Because the majority of the mothers in this study who were depressed at the time of their first child were no longer depressed at the time of their second child, we were interested in whether shifts in positive affect would occur differentially for this group.

\section{Method}

\section{Participants}

Complete data were available for 39 women observed with firstborn and second-born siblings when each was approximately 2 months old (an average of 2.3 and 2.7 months, respectively), $t(37)=-1.52, n s$, with a mean age gap of 24 months. All mothers were Caucasian, married, with an average age of 29 years, and had at least a high school education. Maternal depression was assessed at both time points using the Schedule for Affective Disorders and Schizophrenia modified for a post-partum sample (Campbell, Cohn, \& Meyers, 1995). According to criteria when firstborn infants were 2 months of age, 19 mothers comprised the depressed group and 20 mothers the control group. Of the 19 mothers depressed at the time of their first infant, only 6 met criteria for depression when their second infant was 2 months old. These mothers' episodes of depression were not continuous during the time period between the births of their two children. None of the 6 continued to meet criteria for depression when firstboms were 6 months of age, although all 6 showed subclinical symptomatology at that time. No other mothers besides these 6 experienced a recurrence of depression at the time of their second child.

\section{Procedures}

Mothers and infants were videotaped in their homes for $3 \mathrm{~min}$ in faceto-face play. Mothers' and infants' behaviors were coded separately by trained coders who were blind to mothers' diagnoses and naive to hypotheses regarding birth order and consistency. Combining information from facial and vocal expressions and direction of gaze, six affective states were coded at 1-s time intervals for both mothers and infants, then collapsed to determine the proportion of total interaction time each partner spent in a positive, neutral, or negative affective state (Cohn, Campbell, Matias, \& Hopkins, 1990). For example, mother positive was defined as the proportion of time during the interaction that a mother was smiling or expressed exaggerated, playful affect. Infant negative was defined as the proportion of time an infant was in one of two affectively negative states, one of active protest, the other of a sad or wary state. To assess reliability, $20 \%$ of the interactions of mothers with firstborn infants from the larger sample $(n=133)$ were coded by a second coder. Coders' agreement for positive, neutral, and negative affect was quantified with the kappa statistic ( $\kappa=.73$ for mothers' affect and .78 for infants' affect; Campbell et al., 1995).

To assess maternal perceptions of infant's temperament, mothers were asked a series of questions about their infant's behaviors in the areas of sleep patterns, feeding, irritability, consolability, alertness, adaptability, mood, and cuddliness. Their responses were rated on a 3-point scale, then summed, with higher values indicating a more difficult infant (Campbell et al., 1995). Several questionnaires, including the Infant Characteristics Questionnaire (ICQ; Bates, Freeland, \& Lounsbury, 1979), were left for mothers to complete and to return by mail. Complete data were not available for the ICQ, so interview ratings were used as a measure of infant difficult temperament. Internal consistency of the interview difficultness measure was computed for both firstborn and second-born siblings (Cronbach's alpha $=.82$ and .76 , respectively). Correlation coefficients between the Fussy-Difficult factor from mothers' responses to the ICQ and the interview summary score were .65 for first siblings and .60 for second siblings.

\section{Results}

Rates of maternal and infant negative affect were low (see Table 1). Therefore, only positive affect scores were analyzed. Hereafter, the term affect will refer to positive affect.

\section{Birth Order Effects}

Repeated measures analyses of variance (ANOVAs) were conducted, with diagnosis of depression at the time of the first sibling as the between-groups factor and siblings' ages added as covariates to control for any possible confound of age and birth order. Mothers were more positive, on average, with second-born than with firstborn infants $F(1,37)=33.45, p<$ .001. Second-borns were significantly more positive in interaction with their mothers than were firstborns $F(1,37)=9.70$, $p<.05$. As can be seen in Table 1 , the increase in positive affect for mothers and infants reflected a decrease in neutral affect rather than a decrease in negative affect.

There was no main effect for mother's initial diagnosis of

Table 1

Mean Proportions of Mother and Infant Affect

\begin{tabular}{|c|c|c|c|c|c|c|}
\hline \multirow[b]{3}{*}{ Partner } & \multicolumn{6}{|c|}{ Affect scores } \\
\hline & \multicolumn{2}{|c|}{ Positive } & \multicolumn{2}{|c|}{ Neutral } & \multicolumn{2}{|c|}{ Negative } \\
\hline & $M$ & $S D$ & $M$ & $S D$ & $M$ & $S D$ \\
\hline \multicolumn{7}{|l|}{ Mother with } \\
\hline Sibling 1 & $.62^{\mathrm{a}}$ & .22 & $.36^{a}$ & .21 & .02 & .10 \\
\hline Sibling 2 & $.81^{\mathrm{b}}$ & .17 & $.16^{b}$ & .15 & .04 & .05 \\
\hline \multicolumn{7}{|l|}{ Infant } \\
\hline Sibling 1 & $.14^{\mathrm{c}}$ & .13 & .78 & .13 & .08 & .11 \\
\hline Sibling 2 & $.26^{\mathrm{d}}$ & .20 & .68 & .19 & .06 & .09 \\
\hline
\end{tabular}

Note. Values with different superscripts within columns differ significantly, $p<.05$. 
depression, and, notably, no Group $\times$ Sibling interaction effect, which would have indicated shifts in affect associated with remission of depression. Although the small number precluded statistical analysis, the 6 women who met criteria for depression when they were observed with both firstborn and second-born infants did not appear to differ from the other mothers in the initially depressed group. In fact, these mothers had a slightly higher mean level of positive affect than did women who only met criteria when observed with their first child. In the larger sample of mothers observed with firstborn infants $(n=133)$, effects for depression were found for only a subgroup whose episodes of depression continued beyond their first infant's 6 months of age (Campbell et al., 1995). This subgroup of mothers whose episodes of depression were relatively long lasting did not include those 6 mothers who experienced a recurrence of depression at the time of the birth of their second children.

A significant main effect for depression as well as a Group $x$ Sibling interaction were found for maternal ratings of infant difficultness $F(1,37)=9.69, p<.01$. Mothers in the depressed group rated their firstborns as more difficult than their secondborns and more difficult than control mothers rated firstborn infants. The difference between depressed and control mothers occurred for ratings of firstborns only $(M=5.47$ and 1.30 for depressed and control groups, respectively).

\section{Individual Differences}

Maternal affect was moderately stable between siblings ( $r=$ $.47, p<.01)$. Coefficients did not differ significantly between depressed and control mothers $(r=.48, p<.05$ and $.43, p$ $<.10$, respectively). Infant affect was uncorrelated between siblings. Maternal and infant affect were unrelated to maternal perceptions of difficult temperament. Mother and infant affect were moderately correlated $(r=.48, p<.01$ and $r=.41, p$ $<.05$, with firstborn and second-born infants, respectively).

\section{Predictors of Maternal and Infant Affect}

To determine predictors of maternal and infant affect, a series of multiple regressions was conducted (see Table 2). Mother's affect with her second-born infant was independently predicted by a stable self-component (affect with her firstborn) and by concurrent infant affect $\left(R^{2}=.37\right), F(3,35)=6.76, p<.01$. Regression results were not affected by order in which variables were entered. Figure 1 presents the standardized beta coefficients from the regression analyses. Only concurrent maternal affect was a significant predictor of infant affect $\left(R^{2}=.16\right)$, $F(2,36)=3.52, p<.05$

\section{Discussion}

In this study, we observed mothers in face-to-face play with their firstborn infants at 2 months, then with their second-born infants at the same age. We found stable individual differences in mothers' positive affect in this context, consistent with previous research in which mothers with older infants have been observed (DiLalla \& Bishop, 1996; Dunn \& Plomin, 1986; Dunn et al., 1986; Dunn et al., 1985; Jacobs \& Moss, 1976; Ward et al.,
Table 2

Hierarchical Multiple Regressions Predicting Mothers'

Positive Affect With Second Sibling and

Second Siblings' Positive Affect

\begin{tabular}{|c|c|c|c|}
\hline Equation & $R^{2}$ & $\Delta R^{2}$ & $\Delta F$ \\
\hline \multicolumn{4}{|c|}{ Mother's positive affect with second sibling ${ }^{a}$} \\
\hline \multicolumn{4}{|l|}{ Equation 1} \\
\hline First sibling's affect & .00 & .00 & .09 \\
\hline Mother's affect with first sibling & .26 & .25 & $12.32 * *$ \\
\hline Second sibling's affect & .37 & .11 & $6.09 *$ \\
\hline \multicolumn{4}{|l|}{ Equation 2} \\
\hline First sibling's affect & .00 & .00 & .09 \\
\hline Second sibling's affect & .16 & .16 & $6.95^{*}$ \\
\hline Mother's affect with first sibling & .37 & .20 & $11.24 * *$ \\
\hline \multicolumn{4}{|c|}{ Second sibling's positive affect ${ }^{\mathrm{a}}$} \\
\hline \multicolumn{4}{|l|}{ Equation 1} \\
\hline Mother's affect with first sibling & .04 & .04 & 1.39 \\
\hline Mother's affect with second sibling & .16 & .13 & $5.49 *$ \\
\hline \multicolumn{4}{|l|}{ Equation 2} \\
\hline Mother's affect with second sibling & .16 & .16 & $7.24^{*}$ \\
\hline Mother's affect with first sibling & .16 & .00 & .00 \\
\hline
\end{tabular}

${ }^{a}$ Dependent variable.

$* p<.05 . \quad * * p<.01$

1988 ) and consistent with trait-emotion theories (e.g., Lykken \& Tellegen, 1996). This stability suggests that siblings will experience relatively similar affective interactions with mothers at this early stage of development. It is interesting, though, that this did not appear to be the case.

When we examined factors accounting for maternal and infant affect, we found evidence for systematic variation in response to birth order and to bidirectional influence in the interactions. Although mothers showed a stable affective style when playing face-to-face with infants, they had unique responses to individual children within families that were correlated with the infants' expressions. This pattern of results suggests that, as early as 2 months of age, infants help to shape interactions with their mothers. By observing the same mothers with different partners, we were able to view an active process of social interaction, with mothers and infants jointly constructing the affective exchange.

The interactions we observed were brief, and care must be taken in generalizing these results to the broader mother-infant relationship. Several factors, however, support the generalizability of our findings. First, mother and infant affect are moderately correlated between face-to-face interactions and naturalistic observations in the home (Cohn et al., 1990). Second, the moderate stability that we found in mothers' behavior in face-to-face interaction is consistent with that found in adults' affect across a wide range of contexts (Diener \& Larsen, 1984; Lykken \& Tellegen, 1996). Third, maternal and infant affect in brief, early face-to-face interactions individually predict emotion regulation in the second year (Malatesta et al., 1989). Nevertheless, additional research is needed with regard to these findings.

Finding that mothers were more positive in face-to-face interaction with second-born infants than with their firstborn infants is consistent with the conclusions of other researchers (e.g., 


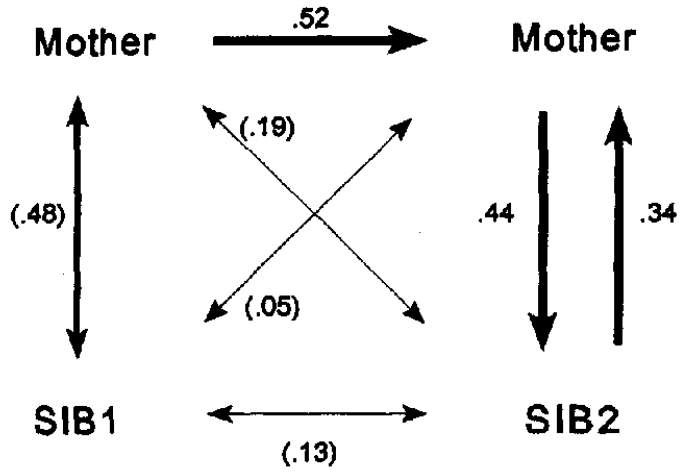

Figure 1. Regression standardized beta coefficients. Only significant beta coefficients are included. Double-headed arrows indicate correlations, and values in parentheses are Pearson correlation coefficients. Bold lines indicate significant coefficients, $p<.05$. Mother $=$ maternal positive affect; SIB1 = first sibling positive affect; SIB2 = second sibling positive affect.

Lewis \& Kreitzberg, 1979; Ward et al., 1988) that experience with child rearing can bring about change associated with greater competence and ease in the role of parenting. The birth order shift also can be interpreted in terms of Lykken's and Tellegen's (1996) set-point theory. The lower level of positive emotion expressed with firstborns may reflect stress and anxiety associated with the transition to parenthood. In this sample, experience and increased competency with child rearing could have returned these mothers relatively quickly to their set point by the time of the birth of their second child.

Because the mothers in this study were observed in face-toface interaction with first siblings a maximum of three times (at 2, 4, and 6 months) before being observed with their second child, it is possible that the greater level of positive affect seen with second siblings was due to a familiarity with the situation. We think this is unlikely. First, other research has indicated that mothers who were videotaped multiple times interacting with their children in various contexts (home or laboratory) were not more or less positive when they were viewed in the same context (Belsky, 1980). Second, if the increase in positive affect were due to greater comfort with the camera, then we would expect to see this effect more clearly over the first three video recordings that were spaced approximately 2 months apart rather than over the average 18 -month gap between the last observation with the first infant and the sibling observation. However, mothers did not become more positive over the period from 2 to 6 months when observed with their first infants (Campbell et al., 1995).

The increase in maternal positive affect with the second sibling was unrelated to remission of depression, and depression did not influence the stability of maternal positive affect. It did, however, affect the perceptions that mothers had of their infants' difficultness. Previous research has not established convincingly whether depressed mothers' perceptions are distorted or accurate (Richters, 1992). This research traditionally compared different groups of depressed and nondepressed mothers. The within-family design of our sibling study offered a unique view of this issue by comparing the perceptions of the same mothers when they were experiencing an episode of depression and when they were not. Because most of the initially depressed mothers were no longer depressed when observed with their second children, and their ratings of infant difficulty systematically decreased, our findings are consistent with the possibility of a negative bias associated with an episode of depression.

Within-family research designs, such as the current study, provide opportunities to understand better the effect of parenting and familial risk factors on child development. On the basis of a traditional, between-family research design, the finding of stable individual differences in maternal affect would have supported the conclusion that children within families experience similar affective experiences with their mother. Looking within families, however, we found that siblings experienced unique affective interactions with their mother as early as 2 months. As these experiences occur repeatedly over time, each motherinfant dyad may construct a unique history of affective interactions that characterizes their relationship. In this way, the early mother-infant affective relationship may be a source of nonshared environmental variation in children's emotional development.

\section{References}

Bates, J. E., Freeland, C. B., \& Lounsbury, M. L. (1979). Measurement of infant difficultness. Child Development, 50, 794-803.

Bell, R. Q. (1968). A reinterpretation of the direction of effects in studies of socialization. Psychological Review, 75, 81-95.

Belsky, J. (1980). Mother-infant interaction at home and in the laboratory: A comparative study. Journal of Genetic Psychology, 137, 3747.

Campbell, S. B., Cohn, J. F., \& Meyers, T. (1995). Depression in firsttime mothers: Mother-infant interaction and depression chronicity. Developmental Psychology, 60, 349-357.

Clark, L. A., Watson, D., \& Mineka, S. (1994). Temperament, personality, and the mood and anxiety disorders. Journal of Abnormal Psychology, 103, 103-116.

Cohn, J. F., Campbell, S. B., Matias, R., \& Hopkins, J. (1990). Face-toface interactions of postpartum depressed and nondepressed motherinfant pairs at 2 months. Developmental Psychology, 26, 15-23.

Diener, E., \& Larsen, R. J. (1984). Temporal stability and cross-situational consistency of affective, behavioral, and cognitive responses. Journal of Personality and Social Psychology, 47, 871-883.

DiLalla, L. F., \& Bishop, E. G. (1996). Differential maternal treatment of infant twins: Effects on infant behaviors. Behavior Genetics, 26, $535-542$.

Dunn, J. \& Plomin, R. (1986). Determinants of maternal behavior towards 3-year-old siblings. British Journal of Developmental Psychology, 4, 127-137.

Dunn, J., Plomin, R., \& Daniels, D. (1986). Consistency and change in mothers' behavior toward young siblings. Child Development, 57, 348-356.

Dunn, J., Plomin, R., \& Nettles, M. (1985). Consistency of mothers' behavior toward infant siblings. Developmental Psychology, 21, $1188-1195$.

Hoffman, L. W. (1991). The influence of the family environment on personality: Accounting for sibling differences. Psychological Bulletin, $110,187-203$.

Jacobs, B. S., \& Moss, H. A. (1976). Birth order and sex of sibling as determinants of mother-infant interaction. Child Development, 47 , $315-322$. 
Kaye, K., \& Fogel, A. (1980). The temporal structure of face-to-face communication between mothers and infants. Developmental Psychology, 16, 454-464.

Lewis, M., \& Kreitzberg, V. S. (1979). Effects of birth order and spacing on mother-infant interaction. Developmental Psychology. 15, 617625 .

Lykken, D., \& Tellegen, A. (1996). Happiness is a stochastic phenomenon. Psychological Science, 7, 186-189.

Malatesta, C. Z., Culver, C., Rich-Tesman, J., \& Shepard, B. (1989). The development of emotion expression during the first two years of life. Monograph of the Society for Research in Child Development, 54 (1-2, Serial No. 219).

Plomin, R. (1994). Genetics and experience: The interplay between nature and nurture. Thousand Oaks, CA: Sage.

Richters, J. E. (1992). Depressed mothers as informants about their children: A critical review of the evidence for distortion. Psychological Bulletin, 112, 485-499.

Tronick, E. Z., Cohn, J. F., \& Shea, E. (1986). The transfer of affect between mothers and infants. In T. B. Brazelton \& M. W. Yogman (Eds.), Affective development in infancy (pp. 11-25). Norwood, NJ: Ablex.

Ward, M. J., Vaughn, B. E., \& Robb, M. D. (1988). Socia]-emotional adaptation and infant-mother attachment in siblings: The role of the mother in cross-sibling consistency. Child Development, 59, 643-651.

Watson, D., Clark, L. A., \& Carey, G. (1988). Positive and negative affectivity and their relation to anxiety and depressive disorders. Journal of Abnormal Psychology, 97, 346-353.

Received March 7, 1996

Revision received January 21, 1997

Accepted January 21, 1997 